\title{
Dental Intrusion
}

National Cancer Institute

\section{Source}

National Cancer Institute. Dental Intrusion. NCI Thesaurus. Code C82127.

A translational form of tooth movement directed apically and parallel to the long axis. 